\title{
'Let's talk about science!' A report on the ÖCSK workshop about making science communication attractive for academics
}

\section{Barbara Heinisch", Rebecca Stocker* and Esther Topitz}

Centre for Translation Studies, University of Vienna, Austria

Gymnasiumstraße 50, 1190 Vienna, Austria

E-mail:barbara.heinisch@univie.ac.at,rebecca.stocker@univie.ac.at,esther.topitz@univie.ac.at

Citizen science and science communication go hand in hand as communication between researchers and participants is crucial in citizen science projects. A workshop about science communication during the ÖCSK 2020 Conference embedded citizen science and science communication in the third mission of universities. It invited participants to join in on a thought experiment based on future thinking and to share their science communication experiences. The results showed that researchers engaging in science communication, especially with the participants in their projects, require competences and resources to do so. However, communication is also relevant within the project team, with other researchers (who are not engaging in citizen science) and traditional media.

Austrian Citizen Science Conference 2020 - ACSC2020

14-16 September 2020

Vienna - Austria

*Speaker 


\section{Introduction}

Science communication and citizen science (CS) are intertwined. Communication is crucial in all phases of a CS project, ranging from the recruitment of participants, answering their questions throughout the project, providing feedback, offering training and reporting on (interim) results. Communication with citizen scientists is not only essential for participant management but also for the quality assurance of data and research. Consequently, researchers need to invest additional efforts and resources in science communication, which in turn is the reason why scholars may be discouraged to engage in science-to-public communication or (mutual) exchange with citizen scientists. However, especially participants in CS projects would wish for this (mutual) exchange with academics.

The objectives of this workshop were, on the one hand, to exchange both successful and unsuccessful approaches to communication between citizens and academics, and on the other hand, to illustrate the added value and benefits of science communication for academia to other academics. By sharing experiences and ideas of how colleagues in a project can be motivated to take this additional effort, the added value of science communication could be highlighted.

After aligning CS and science communication with the third mission of universities, incentives for academics to engage in science communication were addressed in the workshop.

The workshop organisers provided insight into the role of science communicators based on their experience in their own CS project entitled "IamDiÖ - Erforsche Deutsch in Österreich!" and their role as mediators between academics and citizens. As such they have to prepare (teaching and information) materials based on the domain expertise of the researchers, which need to remain academically correct while still being generally comprehensible and didactically appealing to laypersons. At the same time, they also have to inform the researchers about the citizens' needs and expectations (public-to-science communication).

In a workshop held during the Austrian Citizen Science Conference (ÖCSK) 2020, 17 participants shared their experiences of (science) communication in CS projects. By collecting science communication strategies, different solutions to challenges faced by various CS projects as well as their advantages and disadvantages were discussed.

$\mathrm{CS}$ and science communication have a strong relation to the third mission paradigm. While the first two missions of universities are research and teaching, the third mission is the exertion of impact on society [1]. Third mission thus means to generate, use, apply and exploit knowledge and university capabilities beyond academia [2]. This demonstrates that the third mission encompasses more than science communication, since universities have to interact and mutually exchange with persons outside academia. In addition to knowledge and research transfer and continuing education also societal commitment is key [1].

The evaluation of science communication in CS projects is also addressed in the literature [3] as well as the role of science communication as an enabler for "two-way communication, dialogue and engagement" [4].

\section{Method}

The workshop was kicked off with an introductory round: The participants' background ranged from science communication, CS project coordination to persons only interested in CS. However, they had similar science communication experiences. 
The attendees were then invited to join in on a thought experiment based on future thinking [5]. They were asked to project themselves into a future that allowed for their ideal CS project. Then participants were instructed to vividly imagine their projects. In a future, in which they had every opportunity and all resources, in which they were not held back by present restrictions or challenges they were currently facing, how would their project look like? This creative approach of future thinking and the thought experiment's subsequent reflection can help to refine priorities and concentrate on future needs. It also allows to establish positive emotional experience concerning the project's future and thus motivate project members to meet current challenges and work towards the envisioned goals. Following the thought experiment on their project's somewhat utopian future, participants shared their experience of science communication. Three categories were provided: 1) communication with (other) researchers, 2) communication with citizens and 3) communication channels used. For each category, participants provided one successful and one unsuccessful example to be discussed.

\section{Approaches to science communication in citizen science projects}

\subsection{Communication with fellow researchers}

The results of the follow-up discussion show that, although researchers are generally interested in CS, it is often difficult to actually motivate them to partake in and support the relevant CS project through science communication. Therefore, highlighting to colleagues how their own research can benefit from CS can help to promote active involvement.

While universities and researchers acknowledge the importance of third mission activities, often there is no time planned for CS, stated the participants. The reason why colleagues do not engage in science communication and CS was a lack of work capacity, according to the participants.

This ties in with another aspect described by the participants: publications as part of science communication using simplified or non-academic terminology are not being perceived as valuable contributions by the academic community and are often not recognised during a researcher's performance evaluation. Thus, researchers whose workload is already high may choose not to contribute to CS activities.

It was therefore suggested that researchers' performance evaluation should include publications targeting the general public. This might be an incentive for researchers to contribute more to CS, and thus third mission goals.

\subsection{Communication with citizens}

According to the workshop participants, communication with citizens is most successful if there is low-threshold access and direct contact with researchers, whether through science communication events, workshops at schools, via e-mail or phone.

While many persons reported that establishing contact with citizens is already challenging, remaining in contact with citizens and sustaining their interest in research, proves to be even more demanding. 


\subsection{Communication channels}

When asked which communication channels they prefer to conduct CS, most participants agreed that direct conversation and face-to-face interaction with citizens, as well as researchers, work best. Traditional media, such as newspaper articles or radio reports were also considered successful, especially to spark the public's interest in research areas but also concerning the recruitment of participants. Still, workshop participants raised the issue that traditional media tend to simplify academic content which can distort information. Some were apprehensive that publishing non-academic and somewhat 'academically inaccurate' texts might discredit them within the academic community.

Social media channels were reported to be another successful channel of communication. Although activities, such as posting pictures or videos on social media, are received well by citizens, workshop participants identified multiple challenges: It is hard to build up reach and followers particularly for CS projects. CS projects often rely on organic traffic as they do not have the financial resources to pay for advertisements. Moreover, a social media platform can only reach a certain audience. Therefore, it is necessary to use different platforms that have to be handled differently, as some primarily focus on text, others on pictures and/or videos. Further problems with social media mentioned were data protection and copyright issues.

\section{Conclusion}

The workshop participants adopted a wide range of approaches to communication in CS projects. While for some participants personal dialogue and the use of traditional media proved to be successful, others see traditional media as a potential risk since information may be distorted. For all participants, social media was an issue. The workshop results also showed that communication in CS projects is not restricted to communication with laypersons and citizen scientists but also includes communication with researchers in the project, and beyond the project, as well as communication with third parties, such as traditional media. Moreover, framework conditions, such as institutional structures, merit systems and competition play a role. Another issue mentioned by the participants was a lack of capacities for science communication.

Acknowledgment: This research received funding from the Austrian Science Fund (FWF): TCS $57 \mathrm{G}$.

\section{References}

[1] J. Henke, P. Pasternack, S. Schmid, Mission, die dritte: Die Vielfalt jenseits hochschulischer Forschung und Lehre: Konzept und Kommunikation der Third Mission, BWV Berliner Wissenschafts-Verlag, Berlin 2018.

[2] J. Molas-Gallart, A. Salter, P. Patel, A. Scott, X. Duran, Measuring Third Stream Activities: Final Report to the Russell Group of Universities 2002.

[3] N. Constant, L. Roberts, Narratives as a mode of research evaluation in citizen science: understanding broader science communication impacts, JCOM 16 (2017).

[4] B. Trench, Science communication and citizen science: how dead is the deficit model, in 9th International Conference on Public Communication of Science and Technology (PCST) Seoul, South Korea, 17-19 May 2006, 2007. 
[5] OECD, Futures Thinking In Brief,

http://www.oecd.org/site/schoolingfortomorrowknowledgebase/futuresthinking/futuresthinkinginbri ef.htm, 2020. 